Rukiye Doğan Çakıer ๑ Funda Gümüş Özcan ๑

Serdar Demirgan $\odot$ Ertuğrul Okuyan ๑

Ayşin Selcan ๑

\title{
Our Anesthetic Managements in Patients \\ Undergoing Transcatheter Aortic Valve Implantation (TAVI): A Retrospective Study
}

Etik Kurul Onayı: Bağcılar Eğitim ve Araştırma Hastanesi Klinik Araştırmalar Etik Kurulu'ndan onay almıştır (2018.04.1.01.037 / 13.04.2018).

Çıkar çatışması: Yoktur.

Finansal destek: Alınmamıştır.

Hasta onamı: Alınmıştı.
Ethics Committee Approval: Approved by the Bağcılar Training and Research Hospital Clinical Research Ethics Committee (2018.04.1.01.037 / 13.04.2018).

Conflict of interest: None

Funding: None

Informed consent: Obtained

Cite as: Doğan Çakıer R, Gümüş Özcan F, Demirgan S, Okuyan E, Selcan A. Transkateter aort kapak implantasyonu (TAVi) işlemlerinde anestezi yöntemlerimiz: Retrospektif çalışma. GKDA Derg. 2020;26(3):139-46.

öz

Amaç: Transkateter Aort Kapak implantasyonu (TAVi) işlemi, aort darlığı patolojilerinde, konvansiyonel cerrahi için yüksek riskli olgularda uygulanan minimal invaziv bir tekniktir. Anestezi uygulamaları ile net bir görüs olmamakla birlikte, genel, lokal ve sedasyon teknikleri kullanılmaktadır. Bu çalışmada, TAVi işlemlerinde uyguladığımız anestezi yöntemlerimizi ve sonuçlara etkilerini değerlendirmeyi amaçladık.

Yöntem: Kasım 2013 - Aralık 2017 tarihleri arasında ciddi aort darlığı nedeniyle kardiyoloji kliniği tarafından TAVi işlemi uygulanan hastaların arşiv kayıtları incelenerek, uygulanan anestezi yaklaşımları, işleme ait özellikler ve hasta sonuçları değerlendirildi.

Bulgular: 100 (50 kadın/50 erkek) TAVi olgusunun 15'ine genel anestezi (GA), 49'una lokal anestezi-sedasyon (LS), 36'sına lokal anestezi-monitörize anestezi bakımı (LM) uygulanmıştı. $L M$ grubunda, anestezi ve işlem süreleri, GA ve LS gruplarına göre anlamlı şekilde kısaydı $(p<0.05)$. Vazoaktif ajan, sıvı infüzyonu ve yoğun bakım (YBÜ) kalış süreleri GA grubunda yüksekti ( $p<0.05)$. Otuz günlük mortalite tüm gruplarda \%14 iken, GA grubunda mortalite oranı LS ve LM gruplarından anlamlı derecede yüksek bulundu ( $p=0.007)$.

Sonuç: Teknolojik ilerlemeler ve deneyimlerin artışılla, TAVi için GA gereksinimi azalmış ve sağladığı avantajlar ile keskin bir şekilde LS ve LM uygulamalarına kaymıştır. Ancak, iyi hasta sonuçları için anestezi tekniğinden bağımsız olarak, intraoperatif dönemde tüm hastalar yakın takip edilmelidir.

Anahtar kelimeler: transkateter aort kapak implantasyonu, genel anestezi, lokal anestezi, sedasyon, monitörize anestezi

\section{ABSTRACT}

Objective: Transcatheter Aortic Valve Implantation (TAVI) procedure is a minimally invasive technique that have been applied in aortic stenosis pathologies which carry high-risk for conventional surgery. Although there is no definitive consensus on anesthesic applications, general, local anesthesic and sedation techniques are being used. In this study, we aimed to evaluate our anesthesia methods used in TAVI procedures, and their effects on results.

Method: The archive records of patients who underwent TAVI procedure due to the severe aortic stenosis between 2013 and 2017 were analyzed. Anesthesic approaches, features of the procedure, and patient outcomes were evaluated.

Results: Of the 100 (50 women/50 men) patients who underwent TAVI, 15 had general anesthesia (GA) (15\%), and 49 had local anesthesia with sedation (LS) (49\%), and 36 had local anesthesia with monitorized anesthesia care (LM) (36\%). In the LM group, the anesthesia and procedure times were significantly shorter compared to the GA and LS groups $(p<0.05)$. Vasoactive agenst, and fluid infusions were used more frequently and intensive care (ICU) stay were prolonged in the GA $(p<0.05)$. While the 30 -day mortality was $14 \%$ in all groups, the mortality rate in the GA was significantly higher than the LS and LM $(p=0.007)$. Conclusion: With an increase in technological advances and experience, the need GA for TAVI has decreased and the anesthesia technique has shifted sharply to applications of LS and LM with the advantages they provided. However, regardless of the anesthesia technique, all patients should be followed up closely in the intraoperative period for good patient outcomes.

Received/Geliş: 29.07.2020

Accepted/Kabul: 20.08.2020 Published Online/Online yayın: 21.09.2020

Keywords: transcatheter aortic valve implantation, general anesthesia, local anesthesia, sedation, monitorized anesthesia

(C) Telif hakkı Göğüs Kalp Damar Anestezi ve Yoğun Bakım Derneği'ne aittir. Logos Tıp Yayıncılık tarafindan yayınlanmaktadır. Bu dergide yayınlanan bütün makaleler Creative Commons Atff-Gayri Ticari 4.0 Uluslararası Lisansı ile lisanslanmıştı.

Funda Gümüş Özcan

TC. S.B. Başakşehir Çam ve Sakura Şehir Hastanesi, Anesteziyoloji ve Reanimasyon Kliniği, İstanbul, Türkiye fgumus@hotmail.com ORCID: 0000-0003-3264-4356

R. D. Çakıer 0000-0003-2427-3890 T.C. Sağ lık Bakanlığı Hopa Devlet Hastanesi, Anesteziyoloji ve Reanimasyon Kliniği, Artvin, Türkiye

S. Demirgan 0000-0001-8129-5004

A. Selcan 0000-0001-6464-4188

S.B.Ü. Bağcılar Eğitim ve Araştrrma Hastanesi Anesteziyoloji ve Reanimasyon Kliniği Istanbul, Türkiye

E. Okuyan 0000-0002-0626-2939 S.B.Ü. Bağcılar Eğitim ve Araștırma Hastanesi Kardiyoloji Kliniği istanbul, Türkiye 


\section{Giriş}

Transkateter aort kapak implantasyonu (TAVi) işlemleri, aort darlığı (AD) patolojilerinde, cerrahi ve anestezi açısından yüksek riskli kabul edilen hastalarda, konvansiyonel açık cerrahi girişim ile aort kapak replasmanına güvenli bir alternatif tedavi yöntemi olarak ortaya çıkmıştır ${ }^{[1]}$. Güncel olarak, teknolojik gelişmeler ve klinik çalışmalar sonucunda TAVi işlemlerinin, konvansiyonel cerrahi için orta/yüksek riskli olgularda da "Food and Drug Administration" (FDA) tarafından uygun tedavi seçeneği olarak onaylanmaSı, kapsamını genişletmiş ve her geçen yıl daha fazla sayıda hastada uygulanır hâle getirmiştir ${ }^{[2,3]}$. İşlem, minimal invazif özelliğiyle açık cerrahi tekniğe göre hasta için pek çok avantaj sağlarken, işlem boyunca hem ileri yaşta ve ek komorbiditelere sahip yüksek riskli hasta grubu açısından hem de prosedürel basamaklar açısından anesteziyologların yönetmesi gereken pek çok zorluğa da sahiptir. Bu nedenle, işlem başarısı hastalığın ciddiyeti ile ilişkili olsa da, akıcı ve sorunsuz bir ameliyat için anestezik yönetim kilit rol oynar ${ }^{[4]}$. En iyi anestezik yaklaşım ile ilgili ortak bir görüş olmamakla birlikte, genel, sedasyon veya yalnızca lokal anestezik yaklaşımların kullanıldığı teknikler bildirilmiştir ${ }^{[5,6]}$. Biz de çalışmamızda, TAVi işlemleri için uyguladığımız anestezi yöntemlerimizi geriye dönük inceleyerek sonuçlarımızı değerlendirmeyi amaçladık.

\section{GEREÇ ve YÖNTEM}

Bu çalışma, Sağıık Bilimleri Üniversitesi İstanbul Bağcılar Sağlık Uygulama ve Araştırma Merkezi Anesteziyoloji ve Reanimasyon Kliniğinde 13.04.2018 tarihli 2018.04.1.01.037 karar numaralı Etik Kurul onayı ile 2013-2017 tarihleri arasında ciddi AD nedeni ile TAVi işlemi uygulanan 100 hastanın kayıtlarının retrospektif incelenmesiyle yapıldı. Kayıtlardan işleme ve anestezi yönetimine ait özellikler, perioperatif komplikasyonlar, sıvı transfüzyon miktarları, kan replasmanları, işlem süreleri, 30 günlük mortalite ve morbidite, yoğun bakım ünitesi (YBÜ) ve hastanede kalış süreleri değerlendirilerek kaydedildi.

\section{Preoperatif anestezi hazırlığı ve monitörizasyon}

Tüm hastalar preoperatif dönemde, kardiyolog, kalp cerrahı ve anestezistten oluşan konsey tarafından değerlendirildi. İşlemler, kardiyak kateterizasyon ünitesinde floroskopi kılavuzluğunda gerçekleştirildi. Hastalar on iki kanallı elektrokardiyografi (EKG), periferik oksijen satürasyonu $\left(\mathrm{SpO}_{2}\right)$ ile monitörize edildi, periferik venöz kanülasyon (16-18 G) sonrası \%0.09 $\mathrm{NaCl}$ infüzyonu başlandı. Midazolam (1-2 mg iv) ile premedikasyon sonrası lokal anestezi ile radiyal arter kanülasyonu yapılarak invaziv arteriyel kan basıncı monitörize edildi. Santral venöz kateterizasyon rutin olarak uygulanmadı. Hipotermiyi engellemek için ekternal ısıtıcı cihazlar kullanıldı. Her hasta için genel anestezi ve hava yolu ekipmanları, anestezik ve vazoaktif ajanlar, infüzyon pompaları hazır bulunduruldu.

\section{Anestezi yönetimi ve TAVi işlemi}

Kayıtlardan uygulanan anestezi yöntemleri, genel anestezi (GA), lokal anestezi+sedasyon (LS) ve lokal anestezi ile monitörize anestezi bakımı (LM) olarak gruplandırıldı.

Tüm hastaların giriş arteriyal kan gazı ve aktive edilmiş pıhtılaşma zamanı (ACT) değerleri için başlangıç kan örnekleri alındı. Genel anestezi grubunda, anestezi indüksiyonunda $2 \mu \mathrm{g} / \mathrm{kg}^{-1}$ fentanil, $1-2 \mathrm{mg} / \mathrm{kg}^{-1}$ propofol, $0.6 \mathrm{mg} / \mathrm{kg}^{-1}$ rokuronyum ile orotrakeal entübasyon yapılarak, normokapnik ve normoksik koşullar hedeflenecek şekilde ventile edildi. Anestezi idamesinde 1 minimum alveolar konsantrasyon (MAK) sevofluran oksijen / hava karışımı $\left(\mathrm{FiO}_{2}=\% 50\right)$ içinde uygulandı ve aralıklarla fentanil ve rokuronyum ek dozları yapıldı. LS grubunda, işlem alanına yapılan lokal anesteziyle birlikte, midazolam $0.05 \mathrm{mg}$ $\mathrm{kg}$ ve fentanil $1 \mathrm{\mu g} / \mathrm{kg}^{-1}$ iv ile sedasyon sağlandı. İşlem süresince gerekli görüldüğünde, midazolam bolusu (1-3 mg iv), remifentanil infüzyonu (0.025-0.2 $\mu \mathrm{g} / \mathrm{kg}^{-1} / \mathrm{dk}$.) veya propofol infüzyonu $\left(2-5 \mathrm{mg} / \mathrm{kg}^{-1} /\right.$ saat) eklendi, nazal kanül ile 2-3 L/dk. $\mathrm{O}_{2}$ uygulandı. Grup LM' de, işlem alanına yapılan lokal anestezi ile işlem takip edildi. İntraoperatif hipotansiyon için ilk yaklaşım $500 \mathrm{ml}$ kolloid ile sıvı infüzyonu, 5-10 mg iv bolus efedrin, dirençli olgularda 0.03-0.05 $\mu \mathrm{gr} / \mathrm{kg}^{-1} / \mathrm{dk}^{-1}$ 
noradrenalin infüzyonu, bradikardi ise atropin ile tedavi edildi. Hasta ve işlem için gereklilik durumunda genel anesteziye geçildi. TAVi için femoral arter yaklaşım tekniğinde perkütan veya açık cerrahi teknik kullanıldı. Sağ ventriküle pacemaker yerleştirilerek test edildi. Valvüloplasti öncesi 5000 Ü heparin (gerekirse ek doz) ile ACT >250 s olması sağlandı. Protez kapak tipine göre balon predilatasyonu ve hızlı ventriküler uyarılma ile (180-200 atım/dk-1) ventrikül taşikardisi oluşturularak biyoprotez kapak yerleştirildi. Ekokardiyografi veya floroskopi kılavuzluğunda aortografi ve periferik anjiyografi yapılarak kapak pozisyonu, aortik rejürritasyon ve komplikasyonlar değerlendirildi. Vasküler alan perkütan veya cerrahi olarak kapatıldı.

\section{Postoperatif takip}

Tüm hastalar işlem sonunda Koroner YBÜ transfer edilerek takip edildi. Genel anestezi altında işlem uygulanan ve hemodinamik olarak stabil olan olgular YBÜ'de ekstübe edildi.

\section{İstatistiksel analiz}

İstatistiksel analizler NCSS (Number Cruncher Statistical System) 2007 Statistical Software (Utah, USA) paket programı kullanılarak yapıldı. Verilerin değerlendirilmesinde tanımlayıcı istatistiksel metotlar (ortalama standart sapma), normal dağılım gösteren değişkenlerin gruplar arası karşılaştırmalarında tek yönlü varyans analizi, normal dağılım göstermeyen değişkenlerin gruplar arası karşılaştırmalarında, Kruskal Wallis Testi, alt grup karşılaştırmalarında Dunn's çoklu karşılaştırma testi, nitel verilerin karşılaştırmalarında ki-kare testi kullanıldı. Sonuçlar için, $\mathrm{p}<0.05$ düzeyinde istatistiksel olarak anlamlı kabul edildi.

\section{BULGULAR}

TAVi işlemi yapılan 100 (50 erkek-50 kadın) hastanın, $15^{\prime}$ ine (\%15) GA, 49'una (\%49) LS ve 36'sına (\%36) LM tekniklerinin uygulandığı belirlendi. LS tekniği uygulanarak TAVi işlemi başlatılan 10 hastada GA'ye geçilmişti. Bu hastalar GA grubunda değerlendirildi.
Kliniğimizde TAVI için uygulanan anestezi tekniklerininin yıllara göre dağılımı Şekil 1'de gösterilmiştir.

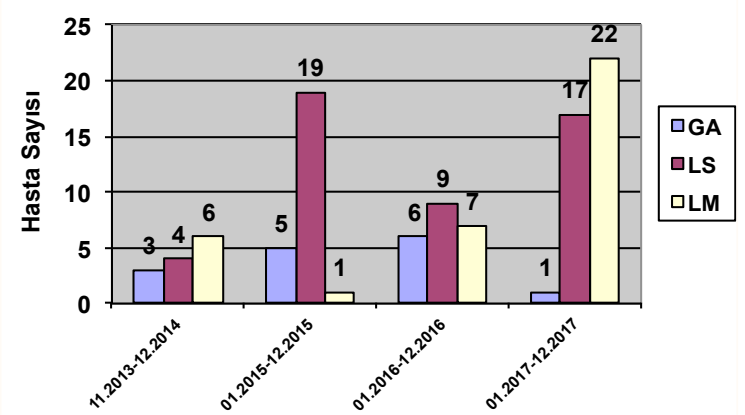

Şekil 1. TAVi işlemi yapılan hastalarda GA, LS ve LM uygulamalarının yıllara göre dağılımları.

Tüm hastalar, ileri yaşta, eşlik eden komorbiditelerle birlikte, Yüksek Amerikan Anestezistler Derneği (ASA), New York Kalp Cemiyeti (NYHA) risk sınıfına, yüksek Amerikan Ulusal Torasik Cerrahi Birliği (STS) Skoru ve Euroskor değerlerine sahipti. Hastalara ait özellikler Tablo 1'de gösterilmiştir.

Transkateter aort kapak implantasyonu için en yaygın kullanılan yöntem olan transfemoral yaklaşım bizim çalışmamızda da 100 hastanın 99'unda kullanılırken, 1 hastada transapikal yaklaşım uygulanmıştı. Anestezi ve işlem süreleri LM grubunda, GA ve LS gruplarından anlamlı derecede kısa bulunurken $(p<0.05), G A$ ve LS grupları arasında ise anlamlı farklılık gözlenmedi (Tablo 2). Intraoperatif kullanılan sıvı infüzyon miktarları GA grubunda istatistiksel olarak anlamlı derecede yüksek bulundu, LS ve LM arsında ise anlamlı farklılık gözlenmedi $(p<0.05$, Tablo 2). Gruplarda uygulanan kan transfüzyon oranları benzerdi (Tablo 2). Her 3 grupta da değişen oranlarda vazoaktif ve/veya inotropik ajan desteği kullanılmakla birlikte, GA grubunda, LM ve LS gruplarına göre anlamlı şekilde yüksek bulundu ( $p<0.05$ Tablo 2$)$.

Genel anestezi uygulanan hastaların tamamı yoğun bakımda ekstübe edildi. Yoğun bakım ünitesi kalış süreleri, GA grubunda, LS ve LM gruplarından anlamIı derecede uzun bulundu. LS ve LM grupları arasında ise anlamlı farklılık gözlenmedi. Üç grubun hastane 
Tablo 1. Hastaların demografik özellikleri, risk sınıfları ve komorbiditeleri.

\begin{tabular}{lcccc} 
Değişkenler & $\begin{array}{c}\text { Grup GA } \\
(\mathbf{n}=\mathbf{1 5})(\%)\end{array}$ & $\begin{array}{c}\text { Grup LS } \\
(\mathbf{n}=\mathbf{4 9 )}(\%)\end{array}$ & $\begin{array}{c}\text { Grup LM } \\
(\mathbf{n}=\mathbf{3 6})(\%)\end{array}$ \\
\hline YIl & $79.33 \pm 7.16$ & $77.06 \pm 6.65$ & $77.72 \pm 7.64$ & P \\
Cinsiyet erkek/kadın & $8(\% 53) / 7(\% 46)$ & $26(\% 53) / 23(\% 47)$ & $16(\% 44) / 20(\% 55)$ & 0.555 \\
Boy (cm) & $165 \pm 0.08$ & $165 \pm 0.09$ & $164 \pm 0.09$ & 0.707 \\
Kilo (kg) & $73.47 \pm 10.82$ & $74.2 \pm 14.43$ & $76.22 \pm 9.7$ & 0.936 \\
EF $<\% 40$ & $2(\% 13)$ & $6(\% 12)$ & $4(\% 11)$ & 0.973 \\
ASA III/IV & $15(\% 100)$ & $43(\% 87) / 6(\% 12)$ & $33(\% 91) / 3(\% 8)$ & 0.344 \\
NYHA III/IV & $7(\% 46) / 8(\% 53)$ & $20(\% 42) / 27(\% 57)$ & $21(\% 58) / 15(\% 41)$ & 0.355 \\
Euro-skor & $31.69 \pm 16.96$ & $24.92 \pm 12.32$ & $24.94 \pm 12.65$ & 0.193 \\
STS skor & $8.41 \pm 3.19$ & $7.15 \pm 3.6$ & $1.22 \pm 3.22$ & 0.437 \\
Geçirilmiş CABG & $3(\% 20)$ & $9(\% 18)$ & $2(\% 5.56)$ & 0.073 \\
KOAH & $4(\% 26.67)$ & $16(\% 32.65)$ & $4(\% 11.11)$ & 0.011 \\
DM & $8(\% 53.33)$ & $13(\% 26.53)$ & $8(\% 22.86)$ & 0.006 \\
KKY & $2(\% 13.33)$ & $11(\% 22.45)$ & $3(\% 8.33)$ & 0.719 \\
KBY & $3(\% 20.00)$ & $5(\% 10.20)$ & $5(\% 13.89)$ & 0.464 \\
SVH & $0(\% 0.00)$ & $3(\% 6.12)$ & \\
\hline
\end{tabular}

p<0.05, ki-kare testi, *Tek Yönlü Varyans Analizi

GA: Genel Anestezi, LS: Lokal Anestezi + Sedasyon, LM: Monitörize Anestezi ımı, KOAH: Kronik Obstrüktif Akciğer Hastalığı, DM: Diabetes Mellitus; KABG: Koroner Arter Bypass Cerrahisi, KKY: Konjestif Kalp Yetmezliği KBY: Kronik Böbrek Yetmezliği, SVH: Serebrovasküler Hastalık, EF: Ejeksiyon fraksiyonu, EuroSCORE: European System for Cardiac Operative Risk Evaluation

kalış süreleri benzerdi (Tablo 2). Otuz günlük mortalite GA'da 6 (\%40), LS'de 5 (\%10.20) ve LM'de 3 (\%8.33) olmak üzere 14 hastada gelişti. Mortalite, GA'da LS ve LM gruplarından anlamlı derecede yüksekti ( $p<0.05$, Tablo 3 ). İşleme bağlı persistan atriyoventriküler blok gelişmesi nedeniyle; LS'de 5, LM grubunda 3 hastaya kalıcı pil yerleştirildi
(Tablo 3).

Perioperatif GA'da 3, LS ve LM gruplarında birer hastada kardiyak komplikasyonlar gelişmesi nedeni ile acil sternotomi gerekti. Acil kardiyovasküler cerrahi gerekliliği GA'da yüksek bulunurken diğer komplikasyonların dağılım oranları benzer tespit edildi (Tablo 3).

Tablo 2. Işleme ve anesteziye ait özellikler.

\begin{tabular}{lcccc} 
Değişkenler & $\begin{array}{c}\text { Grup GA } \\
(\mathbf{n = 1 5 )}\end{array}$ & $\begin{array}{c}\text { Grup LS } \\
(\mathbf{n = 4 9 )}\end{array}$ & $\begin{array}{c}\text { Grup LM } \\
(\mathbf{n = 3 6 )}\end{array}$ & p* değeri \\
\hline İşlem süresi (dk.) & $125.33 \pm 38.15$ & $124.08 \pm 43.99$ & $91.67 \pm 32.91$ & 0.001 \\
Anestezi süresi (dk.) & $152.33 \pm 38.07$ & $148.57 \pm 43.6$ & $118.06 \pm 33.43$ & 0.001 \\
Kullanılan sıVı miktarı (ml) & $1510 \pm 342.37$ & $615.31 \pm 140.76$ & $595.83 \pm 160.97$ & 0.0001 \\
Kan Transfüzyonu (ES) & $5(\% 33.33)$ & $8(\% 16.33)$ & $4(\% 11.11)$ & 0.154 \\
İnotrop/Vazopressör/Vazodilatör ajan gereksinimi & & & $0(\% 0.00)$ & 0.301 \\
$\quad$ Dobutamin & $1(\% 6.67)$ & $1(\% 2.04)$ & $1(\% 2.78)$ & 0.0001 \\
Dopamin & $5(\% 33.33)$ & $0(\% 0.00)$ & $0(\% 0.00)$ & 0.0001 \\
$\quad$ Norepinefrin & $4(\% 26.67)$ & $0(\% 0.00)$ & $1(\% 2.78)$ & 0.0001 \\
Atropin & $7(\% 46.67)$ & $3(\% 6.12)$ & $0(\% 0.00)$ & 0.0001 \\
$\quad$ Adrenalin & $7(\% 46.67)$ & $1(\% 2.04)$ & $2(\% 5.56)$ & 0.01 \\
$\quad$ Efedrin & $3(\% 20.00)$ & $3(\% 6.12)$ & $1(\% 2.78)$ & 0.262 \\
$\quad$ Nitrogliserin & $2(\% 13.33)$ & $6(\% 12.24)$ & $1.75 \pm 0.84$ & 0.021 \\
Yoğun bakım kalış süresi (Gün) & $6.47 \pm 13.81$ & $2.47 \pm 2.34$ & $4.22 \pm 2.54$ & 0.282 \\
Hastane kalış süresi (Gün) & $4.27 \pm 4.91$ & $5.45 \pm 4.16$ & $3(\% 8.33)$ & 0.007 \\
Mortalite & $6(\% 40.00)$ & $5(\% 10.20)$ & & \\
\hline
\end{tabular}

Postoperatif ilk 30 günlük dönemde gerçekleşen ölümler değerlendirmeye alındı.

*ki-kare testi, $p<0.05$ : Anlamlı farklılık 
Tablo 3. Komplikasyonlar.

\begin{tabular}{lcccc} 
Komplikasyonlar & $\begin{array}{c}\text { Grup GA } \\
(\mathbf{n = 1 5 )}\end{array}$ & $\begin{array}{c}\text { Grup LS } \\
(\mathbf{n = 4 9 )}\end{array}$ & $\begin{array}{c}\text { Grup LM } \\
(\mathbf{n = 3 6 )}\end{array}$ \\
\hline Kalıcı pacemaker gereksinim & $0(\% 0.00)$ & $5(\% 10.20)$ & $3(\% 8.33)$ & 0.442 \\
Vasküler komplikasyonlar (minör) & $2(\% 13.33)$ & $2(\% 4.08)$ & $2(\% 5.56)$ & 0.414 \\
Acil kardiyovasküler cerrahi & $3(\% 20.00)$ & $1(\% 2.04)$ & $1(\% 2.78)$ & $0.015 *$ \\
Paravalvüler kaçak & $0(\% 0.00)$ & $0(\% 0.00)$ & $1(\% 2.78)$ & 0.407 \\
Postop ABY & $1(\% 6.67)$ & $2(\% 4.08)$ & $1(\% 2.78)$ & 0.811 \\
Postop SVO & $0(\% 0.00)$ & $1(\% 2.04)$ & $0(\% 0.00)$ & 0.591 \\
\hline
\end{tabular}

Postoperatif ilk 30 günlük dönemde gözlenen komplikasyonlar değerlendirmeye alındı.

*ki-kare testi, $p<0.05$ : Anlamlı farklılık

\section{TARTIŞMA}

Transkateter aort kapak implantasyonu işlemlerinde anestezik yaklaşımlar, ekibin deneyimine, hastanın sistemik komorbiditelerine ve kapak implantasyonu için seçilmiş yaklaşım tekniklerine bağlı olarak değişmektedir ${ }^{[7,8]}$. Transkateter aort kapak implantasyonu uygulamaları için GA, loko-rejyonel anestezi, sedasyon ve monitörize anestezi bakımı gibi anestezi yöntemleri tanımlanmıştır ${ }^{[8,9]}$ Bizim çalışmamızda da TAVi işlemleri için GA, LS ve LM teknikleri kullanılmış olup, her 3 tekniğin de TAVi işlemi için uygulanabilir olduğu gösterilmiştir.

TAVI'nin başlatıldığı ilk yıllarda kullanılan kateter ve iletim sistemlerinin boyutları ve çapları nedeniyle ciddi bir cerrahi girişim gerektirdiği, bu durumun GA uygulamalarını zorunlu kıldığı bildirilmiştir [9]. GA, hasta stabilitesi sağlayarak, operatörün daha rahat çalışmasını ve işleme ait komplikasyonların yönetimini kolaylaştırmaktadır ${ }^{[6,9]}$. Ekip deneyiminin öneminin vurgulandığı ilk TAVi çalışmalarında da, TAVi işlemine yeni başlayan, düşük olgu sayısına sahip kliniklerde GA'nın en uygun ve en güvenli anestezi tekniği olduğu vurgulanmıştır ${ }^{[10,11]}$. Ancak günümüzde, TAVi uygulamaları artık yeni bir tedavi şekli olmaktan çıkmış, pek çok merkezde rutin hâle gelmiştir. Yeni geliştirilen perkütan cihaz özellikleri ve ekip deneyimlerinin artışı ile de GA gereksinimleri azalmıştır ${ }^{[9,12]}$. Bizim çalışmamızda da literatür ile uyumlu olarak, ilk TAVI uygulamalarımızda GA kullanılırken, ekip deneyimi arttıkça LS ve LM teknikleri daha sık kullanılmıştı.
Çalışmamızda, LS ve LM tekniklerinin yüksek oranda kullanılmasının bir diğer nedeni de, bu tekniklerin kullanımına olanak sağlayan ve TAVi işlemleri için en yaygın kullanılan transfemoral yaklaşım tekniğinin olgularımızda da en fazla kullanılan yöntem olmasıydı.

Billings ve ark. ${ }^{[13]}$ TAVi işlemlerinde transözefageal ekokardiyografi (TÖE) kullanımının GA'yi zorunlu kıldığını bildirmişlerdir. Ancak, TÖE yerine, anjiografik görüntüleme de aynı klinik ve hemodinamik sonuçları yansıtabilir ${ }^{[14]}$. Bizim çalışmamızda da TEE'nin rutin kullanılmaması ve anjiyografik görüntüleme tercih edilmesi LS ve LM tekniklerinin daha fazla kullanımına ayrıca olanak sağlamıştı.

Sedasyon teknikleri ile işlem sürelerinin önemli derecede kısaldığı gösterilmiştir ${ }^{[5]}$. İşlem süresini, STS / ACC TVT Registry "I "Şlem başlangııından odadan çıkana kadar geçen süre" olarak tanımlar. GA uygulamalarında hasta hazırlığı ve ekstübasyon için gereken süre, uzayan işlem süreleri ile sonuçlanır. Literatürde işlem sürelerinin GA uygulamalarında daha uzun olduğu, lokal anestezi uygulamalarının bu süreleri anlamlı şekilde kısalttığı bildirilmiştir [15,16]. Bizim çalışmamızda da, en kısa işlem ve anestezi süreleri LM grubunda idi.

Çalışmalarda, preoperatif dönemde diüretik tedavi alan hastalarda, hipovolemi ile birlikte GA'nin kardiyak depresan ve vazodilatör etkileri nedeniyle sol ventrikül ön yük yeterliliği için daha fazla volüm infüzyonu gerektirdiği bildirilmiştir ${ }^{[17,18]}$. Bizim çalış- 
mamızda da, GA grubunda intraoperatif sıvı kullanımı anlamlı şekilde fazla idi. Literatürde, GA'nın LS ve LM uygulamalarına göre inotropik destek gereksinimini arttırdığı, ciddi hemodinamik insitabilite nedeniyle en az 2 vazoaktif ilaç infüzyonu gerektiği de bildirilmiştir ${ }^{[19-22]}$. Bizim çalışmamızda da, benzer şekilde intraoperatif vazoaktif ajan desteği GA grubunda daha fazla iken, en az gereksinim LM grubundaydı.

Transfemoral yaklaşımla TAVi uygulanan 10.997 hastalık retrospektif bir çalışmada, sedasyon uygulamaları ile hastane ve YBÜ kalış sürelerinin daha kısa olduğu gösterilmiştir ${ }^{[23]}$. Bu çalışma, TAVi için sedasyon uygulamaları ile hastanede ve YBÜ kalış sürelerinin azaldığını gösteren önceki çalışmaların sonuçlarını doğrulamıştır ${ }^{[18,24,25]}$. Bizim çalışmamızda da, LS ve LM gruplarının YBÜ kalış süreleri, GA grubundan kısa iken, 3 grubun hastane kalış süreleri arasında ise fark gözlenmedi.

Sedasyon uygulamalarının TAVi işlemlerinde morbidite-mortalite oranlarını da etkilediği, lokal anestezi ve sedasyon uygulamalarında 30 günlük mortalitenin azaldığı bildirilmiştir ${ }^{[21,24,26]}$. Bizim çalışmamızda da, literatürle benzer şekilde LS ve LM uygulanan gruplarda, GA grubuna göre mortalite oranları daha düşük bulundu. Literatürde ayrıca, lokal anestezi ve sedasyon tekniklerinden \%7-20 oranlarında acil GA' ye geçiş olduğu ve bunun en önemli nedenlerinden birinin ciddi prosedürel komplikasyonlar olduğu gösterilmiş, bu durumun kötü prognozu belirlediği bildirilmiştir ${ }^{[23-26]}$. Bizim çalışmamızda da, GA uygulanan hastaların mortalite oranları diğer gruplardan anlamlı olarak yüksek bulundu. Bu durum, çalışmamızda LS ve LM tekniği ile başlatılan, ancak işleme ait ciddi komplikasyonlar nedeni ile gerçekleşen ciddi hemodinamik instabilite nedeniyle GA'ya geçilen 10 hastanın GA grubunda değerlendirilmesi ve GA grubunun en yüksek cerrahi risk skorlarına sahip olmasından kaynaklanıyor olabilir.

Villablanca ve ark. ${ }^{[21]}$ TAVi işlemlerinde $G A$ ve $L A$ uygulamalarında, inme, kardiovasküler mortalite, kalıcı pacemaker gereksinimi, vasküler komplikasyonlar ve anüler rüptür gibi komplikasyonlarda fark olmadığını bildirmiştir. Eskandari ve ark. ${ }^{[9]}$ da, komplikasyonların anestezi şekli ile ilişkili olmadığını göstermişlerdir. Çalışmamızda da, minör vasküler komplikasyonlar, sepsis, pnömoni, akut böbrek yetmezliği, enfeksiyon ve serebrovasküler olay (SVO) gibi komplikasyonlar açısından fark yokken, işleme ait komplikasyonlar nedeni ile (ani rüptür, tamponad gibi) GA'ye geçilen ve bu grupta değerlendirilen GA grubunda acil kardiyovasküler cerrahi gerekliliği daha yüksekti. Literatürde paravalvüler kaçak (PVK) ve kalıcı pacemaker (KPM) gereksinimi gibi komplikasyonlar ise, lokal anestezi uygulamalarında daha yüksek oranlarda bildirilmiş ve bunun nedeni, lokal anestezi altında hastaların sağ ventrikülün pace edildiği dönemi tolere edememeleri ve bu nedenle kardiyoloğun işlemi hızlandırması olarak gösterilmiştir [27]. Çalışmamızda, KPM ve PVK insidansında gruplar arası anlamlı farklılık olmasa da, KPM, LS grubunda 5 , LM grubunda 3 hastada gerekti. PVK ise yalnızca LM grubunda 1 hastada görüldü. TAVi işlemi her ne kadar minimal invazif olsa da, gelişebilecek komplikasyonlar nedeni ile ortak komisyon kararlarına ve ASA standartlarına göre, hasta güveniği için işlemlerin deneyimli bir anesteziyolog olmadan yapılmaması gerektiği vurgulanmıştır ${ }^{[28]}$.

Sonuç olarak, TAVi işlemleri günümüzde, ciddi aort darlığı olup, cerrahi için uygun olmayan yüksek riskli hastalarda başarılı bir tedavi şekli olarak uygulanmaktadır. Bu işlemlerde LS ve LM teknikleri gelişen teknolojik ekipman, artan tecrübe ve GA'ya göre sağladığı avantajlar ile birlikte güvenle uygulanabilmektedir. Başarılı hasta sonuçları için anestezi tekniği her ne olursa olsun hastaların preoperatif kapsamlı değerlendirilerek hazırlanması, hasta ve cerrahi işlem gereklilikleri doğrultusunda en uygun anestezi tekniğinin seçilmesi ve intraoperatif yakın takip edilmesi gerekir.

\section{KAYNAKLAR}

1. Wang $\mathrm{HQ}$, Zhang $\mathrm{X}$, Zhang TZ. Advances in the 
anesthetic management of transcatheter aortic valve implantation. J Cardiothorac Vasc Anesth. 2018;32(3): 1464-7.

https://doi.org/10.1053/j.jvca.2017.07.014

2. Leon MB, Smith CR, Mack MJ, Makkar RR, Svensson LG, Kodali SK et al. Transcatheter or surgical aortic- valve replacement in intermediate-risk patients. N Engl J Med. 2016;374:1609-20.

https://doi.org/10.1056/NEJMoa1514616

3. Reardon MJ, Van Mieghem NM, Popma JJ, Kleiman NS, Søndergaard L, Mumtaz M et al. Surgical or transcatheter aortic-valve replacement in intermediate risk patients. N Engl J Med. 2017 Apr 6;376(14):132131. https://doi.org/10.1056/NEJMoa1700456

4. Nagaraja V, Raval J, Eslick GD, Ongt ATL. Transcatheter versus surgical aortic valve replacement: a systematic review and meta-analysis of randomised and nonrandomised trials. Open Heart 2014;1:e000013. https://doi.org/10.1136/openhrt-2013-000013

5. Neuburger PJ, Patel PA. Anesthetic techniques in transcatheter aortic valve replacement and the evolving role of the anesthesiologist. J Cardiothorac Vasc Anesth. 2017;31:2175-82.

https://doi.org/10.1053/j.jvca.2017.03.033

6. Brecker SJ, Bleiziffer S, Bosmans J, Gerckens U, Tamburino C, Wenaweser P, et al. Impact of anesthesia type on outcomes of transcatheter aortic valve implantation (from the Multicenter ADVANCE Study). Am J Cardiol. 2016 Apr 15;117(8):1332-8.

https://doi.org/10.1016/j.amjcard.2016.01.027

7. Lindman BR, Pibarot $P$, Arnold SV, Suri R, McAndrew TC, Maniar HS, et al. Transcatheter versus surgical aortic valve replacement in patients with diabetes and severe aortic stenosis at high risk for surgery: an analysis of the PARTNER 13 Trial (Placement of Aortic Transcatheter Valve). J Am Coll Cardiol. 2014 March 25; 63(11):1090-9. https://doi.org/10.1016/j.jacc.2013.10.057

8. Fassl J. Transcatheter aortic valve implantation should be performed with general anesthesia. J Cardiothorac Vasc Anesth. 2012;26:733-5. https://doi.org/10.1053/j.jvca.2012.02.010

9. Eskandari M, Aldalati O, Dworakowski R, A Byrne J, Alcock $E$, Wendler $O$, et al. Comparison of general anaesthesia and non-general anaesthesia approach in transfemoral transcatheter aortic valve implantation, Heart. 2018;104:1621-8. https://doi.org/10.1136/heartjnl-2017-312559

10. Ruggeri L, Gerli C, Franco A, Barile L, Magnano di San Lio MS, Villari N, et al. Anesthetic management for percutaneous aortic valve implantation: an overview of worldwide experiences. HSR Proc Intensive Care Cardiovasc Anesth. 2012;4:40-6.

11. Covello RD, Maj G, Landoni G, Maisano F, Michev I, Guarracino F, Alfieri O, et al. Anesthetic management of percutaneous aortic valve implantation: focus on challenges encountered and proposed solutions. J
Cardiothorac Vasc Anesth. 2009;23:280-5.

https://doi.org/10.1053/j.jvca.2008.12.017

12. Çiftçi $A$, Kesimci E, Gümüş T, Erkılıç E, Kurtulgu N, Özcan A ve ark. Lokal anestezi ve sedasyon altında yapılan transkateter aort kapak cerrahisi hastalarındaki anestezi deneyimlerimiz. GKDA Derg. 2014;20(4): 202-8.

13. Billings FT, Kodali SK, Shanewise JS. Transcatheter aortic valve implantation: anesthetic considerations. Anesth Analg. 2009 May;108(5):1453-62. https://doi.org/10.1213/ane.0b013e31819b07ce

14. Bagur R, Rodes-Cabau J, Doyle D, De Larochelliere R, Villeneuve J, Lemieux J, et al. Usefulness of TEE as the primary imaging technique to guide transcatheter transapical aortic valve implantation. JACC Cardiovasc Imaging. 2011;4(2):115-24.

https://doi.org/10.1016/j.jcmg.2010.10.009

15. Petronio AS, Giannini C, De Carlo M, Bedogni F, Colombo A, Tamburino $C$, et al. Anaesthetic management of transcatheter aortic valve implantation: results from the Italian Core Valve registry. Euro Intervention 2015;16:20140605-02 https://doi.org/10.4244/EIJY15M03 05.

16. Akbaş S, Özkan AS. General Anesthesia versus local anesthesia plus sedation in high risk patients underwent Transcatheter Aortic Valve Implantation (TAVI): A Retrospective Cohort Study. GKDA Derg. 2019;25(1):4351. https://doi.org/10.5222/GKDAD.2019.26213

17. Guarracino F, Baldassarri R. The anesthetic Management of transcatheter aortic valve implantation. Semin Cardiothorac Vasc Anesth. 2016;20:141-6. https://doi.org/10.1177/1089253215606220

18. Guarracino F, Landoni G. Con: transcatheter aortic valve implantation should not be performed under general anesthesia. J Cardiothorac Vasc Anesth. 2012;26:736-9. https://doi.org/10.1053/j.jvca.2012.01.052

19. Bergmann L, Kahlert P, Eggebrecht $\mathrm{H}$, et al. Transfemoral aortic valve implantation under sedation and monitored anaesthetic care--a feasibility study. Anaesthesia 2011;66(11):977-82. https://doi.org/10.1111/j.1365-2044.2011.06788.x

20. Covello RD, Maj G, Landoni G, Maisano F, Michev I, Guarracino $F$, et al. Anesthetic management of percutaneous aortic valve implantation: focus on challenges encountered and proposed solutions. J Cardiothorac Vasc Anesth. 2009;23:280-5. https://doi.org/10.1053/j.jvca.2008.12.017

21. Villablanca PA, Mohananey D, Nikolic K, Bangalore S, Slovut DP, Mathewet V, et al. Comparison of local versus general anesthesia in patients undergoing transcatheter aortic valve replacement: A metaanalysis. Catheter Cardiovasc Interv. 2018;1;91(2):33042. https://doi.org/10.1002/ccd.27207

22. Guinot PG, Depoix JP, Etchegoyen L, Benbara A, Provenchere S, Dilly MP, et al. Anesthesia and 
perioperative management of patients undergoing transcatheter aortic valve implantation: analysis of 90 consecutive patients with focus on perioperative complications. J Cardiothorac Vasc Anesth. 2010;24: 752-61.

https://doi.org/10.1053/j.jvca.2009.12.019

23. Hyman MC, Vemulapalli S, Szeto WY, et al. Conscious sedation versus general anesthesia for transcatheter aortic valve replacement: Insights from the National Cardiovascular Data Registry Society of Thoracic Surgeons/American College of Cardiology Transcatheter Valve Therapy Registry. Circulation. 2017;136(22):213240.

https://doi.org/10.1161/CIRCULATIONAHA.116.026656

24. Yamamoto M, Meguro K, Mouillet G, Bergoend E, Monin JL, Lim P, et al. Effect of local anesthetic management with conscious sedation in patients undergoing transcatheter aortic valve implantation. Am J Cardiol. 2013;1;111(1):94-9.

https://doi.org/10.1016/j.amjcard.2012.08.053

25. Ben-Dor I, Looser PM, Maluenda G, Weddington TC,
Kambouris NG, Barbash IM, et al. Transcatheter aortic valve replacement under monitored anesthesia care versus general anesthesia with intubation. Cardiovascular Revascularization Medicine, 2012, 13(4):207-210.

https://doi.org/10.1016/j.carrev.2012.02.002

26. Gauthier C, Astarci P, Baele P, Matta A, Kahn D, Keferet $\mathrm{J}$, et al. Mid-term survival after transcatheter aortic valve implantation: Results with respect to the anesthetic management and to the access route (transfemoral versus transapical). Ann Card Anaesth. 2015;18:343-51. https://doi.org/10.4103/0971-9784.159804

27. Maas EH, Pieters BM, Van de Velde M, Rex S. General or local anesthesia for TAVI? A systematic review of the literature and meta-analysis. Curr Pharm Des 2016;22(13):1868-78. https://doi.org/10.2174/1381612822666151208121825

28. Hamid A. Anesthesia for cardiac catheterization procedures. Heart, Lung and Vessels 2014;6(4):22531. 